\title{
The effects of, and interactions between, Cardinium and Wolbachia in the doubly infected spider mite Bryobia sarothamni
}

\author{
VID Ros and JAJ Breeuwer \\ Evolutionary Biology, Institute for Biodiversity and Ecosystem Dynamics, University of Amsterdam, Amsterdam, The Netherlands
}

\begin{abstract}
Many arthropods are infected with vertically transmitted, intracellular bacteria manipulating their host's reproduction. Cytoplasmic incompatibility $(\mathrm{Cl})$ is commonly observed and is expressed as a reduction in the number of offspring in crosses between infected males and uninfected females (or females infected with a different bacterial strain). $\mathrm{Cl}$ is often related to the presence of Wolbachia, but recent findings indicate that a second reproductive parasite, Cardinium, is also capable of inducing $\mathrm{Cl}$. Although both Wolbachia and Cardinium occur in arthropods and may infect the same host species, little is known about their interactions. We observed Wolbachia and Cardinium in the sexual spider mite Bryobia sarothamni (Acari: Tetranychidae) and investigated the effects of both bacteria on reproduction. We performed all possible crossing combinations using naturally infected strains, and show that Cardinium induces strong $\mathrm{Cl}$,
\end{abstract}

expressed as an almost complete female mortality. $B$. sarothamni is the third host species in which Cardiniuminduced $\mathrm{Cl}$ is observed, and this study reveals the strongest $\mathrm{Cl}$ effect found so far. Wolbachia, however, did not induce $\mathrm{Cl}$. Even so, Cl was not induced by doubly infected males, and neither singly Wolbachia-infected nor doubly infected females could rescue $\mathrm{Cl}$ induced by Cardinium-infected males. Possibly, this is related to the differences between Cardinium strains infecting singly and doubly infected individuals. We found a cost of infection in single infected individuals, but not in doubly infected individuals. We show that infection frequencies in field populations ranged from completely uninfected to a polymorphic state. In none of the populations infections were fixed.

Heredity (2009) 102, 413-422; doi:10.1038/hdy.2009.4; published online 18 February 2009

Keywords: cytoplasmic incompatibility; spider mites; endosymbionts; multiple infections; reproductive parasites; symbiosis

\section{Introduction}

Vertically transmitted, intracellular bacteria that manipulate their host's reproductive mode and thereby enhance their own spread are termed reproductive parasites (O'Neill et al., 1997). These manipulations include male killing, feminization, thelytokous parthenogenesis and cytoplasmic incompatibility (CI), and result in an increased proportion of infected females (the transmitting sex) in the host population. CI is the most common effect associated with reproductive parasites (O'Neill et al., 1997; Stouthamer et al., 1999). It is observed in crosses between infected males with females that are either uninfected (unidirectional CI) or infected with a different, incompatible symbiont strain (bidirectional CI). All other crosses are compatible. In this way, the fitness of uninfected or differentially infected females is reduced compared to the fitness of infected females. As a result, the infection will spread.

Cytoplasmic incompatibility is the result of paternal genome fragmentation in fertilized eggs. The exact

Correspondence: Dr VID Ros, Department of Biology, University of Pennsylvania, Leidy Laboratories 326, 433 South University Avenue, Philadelphia, PA 19104-6018, USA.

E-mail:veraros@sas.upenn.edu

Received 7 August 2008; revised 21 November 2008; accepted 20

December 2008; published online 18 February 2009 mechanisms of CI are unknown, but its cytological effects are clear. The mechanism conforms to a 'modification-rescue' system (Hoffmann and Turelli, 1997; Werren, 1997). Sperm is modified in the testes, and as a result, the paternal chromosomes show improper segregation during early mitotic divisions (Breeuwer and Werren, 1990; Reed and Werren, 1995; Tram et al., 2006). This modification is 'rescued' if appropriate symbiont strains are present in the egg. Thus, fertilization is successful when both male and female are infected by symbiont strains with the same modification-rescue system. Strains that can both modify and rescue are typed as $\bmod ^{+} \mathrm{resc}^{+}$. Other strain types, such as strains that do not modify but are capable of rescuing $\left(\bmod ^{-} \mathrm{resc}^{+}\right)$or strains that neither modify nor rescue $\left(\bmod ^{-}\right.$resc $\left.^{-}\right)$, exist as well. (Bourtzis et al., 1998; Merçot and Poinsot, 1998; Vala et al., 2002; Zabalou et al., 2004). $\mathrm{CI}$ leads to a reduction in the number of surviving hybrid offspring. In diploid host species, this is expressed by increased $F_{1}$ mortality. Usually, the embryos die before hatching, and therefore an increased number of unhatched eggs is observed (Hoffmann and Turelli, 1997). In haplodiploid host species, two types of CI effectsincreased female mortality (the hybrid sex in haplodiploids) and increased male production-have been described (Breeuwer and Werren, 1993; Breeuwer, 1997; Vavre et al., 2000; Bordenstein et al., 2003; Mouton et al., 2005). In the latter case, fertilized eggs develop as 
normal, haploid, males after complete elimination of the paternal chromosomes.

Cytoplasmic incompatibility caused by intracellular bacteria has been shown in a large number of arthropods (O'Neill et al., 1997; Werren, 1997; Stouthamer et al., 1999). In the majority of cases, CI was related to the presence of the endosymbiont Wolbachia, a genus in the $\alpha$-Proteobacteria. Wolbachia is widespread among arthropods and nematodes. It is estimated that more than $20 \%$ of all arthropods are infected with Wolbachia (Werren et al., 1995; Breeuwer and Jacobs, 1996; Jeyaprakash and Hoy, 2000; Hilgenboecker et al., 2008). Wolbachia is involved in causing CI in many insects, isopods and mites (reviewed by Stouthamer et al., 1999). More recently, CI was found to be associated with the endosymbiont Cardinium, which belongs to the Cytophaga-Flavobacterium-Bacteroides phylum, a phylum that is unrelated to the $\alpha$-Proteobacteria. Cardinium has so far been found in 6-7\% of all arthropods, and seems to be more common in chelicerates than in insects (Weeks et al., 2003; Zchori-Fein and Perlman, 2004; Duron et al., 2008). Cardinium is the first bacterium other than Wolbachia that causes CI (Hunter et al., 2003). Only two cases of Cardinium-induced CI have been found so far - in the parasitoid wasp Encarsia pergandiella (Hunter et al., 2003), and in the spider mite Eotetranychus suginamensis (Gotoh et al., 2006).

Cardinium and Wolbachia have been found coinfecting the same host species (Weeks et al., 2003; Zchori-Fein and Perlman, 2004; Gotoh et al., 2006; Duron et al., 2008). Although both Cardinium and Wolbachia can manipulate their host's reproductive system, little is known about their interactions. In this study, we investigate the effects of both Wolbachia and Cardinium, and their interactions, in the sexually reproducing spider mite Bryobia sarothamni, using isofemale lines obtained from naturally infected individuals. This phytophagous mite species feeds on common broom (Cytisus scoparius), and we detected both Wolbachia and Cardinium in this mite species. We test whether both bacteria independently induce CI, whether they are mutually incompatible (bidirectional CI), whether CI is induced in doubly infected individuals, and whether one bacterium can rescue $\mathrm{CI}$ induction of the other (see Figure 1 for an overview of tested hypotheses). We additionally investigate the distribution and infection frequency of both bacteria in five populations.

\section{Materials and methods}

\section{Sample collection}

Bryobia sarothamni mites were collected from C. scoparius plants from five European populations in July and August 2006 (Table 1). Populations from Vireux (FR16) and Vierves sur Viroin (BEL5 and BEL6) are less than $5 \mathrm{~km}$ apart, whereas the other two populations from Piriac sur Mer (FR21) and Schoorl (NL17) were more distant from each other and from the aforementioned populations. Individual mites (male and female) were either immediately analyzed in the laboratory to assess the infection frequency (see below), or individual females were reared as isofemale lines in a controlled climate room $\left(20^{\circ} \mathrm{C}, 60 \%\right.$ relative humidity and $16 \mathrm{~L}: 8 \mathrm{D}$ photoperiod). Isofemale lines were initiated by putting a single adult female on a single $C$. scoparius branch. Individual branches were placed in water-soaked square blocks of florist's foam covered with parafilm. Foam blocks were placed in plastic trays filled with water. Females were allowed to lay eggs for 1-2 weeks and were subsequently analyzed in the laboratory for infection status (see below). Two doubly infected (Wolbachia and Cardinium; $I_{\mathrm{WC}}$ ), four singly Wolbachia-infected $\left(\mathrm{I}_{\mathrm{W}}\right)$, one singly Cardiniuminfected $\left(I_{C}\right)$, and two uninfected lines $(\mathrm{U})$ were selected and maintained for subsequent experiments (Table 1). For each of these isofemale lines, the infection status was checked during the course of the experiments by testing randomly picked individuals for infection. No changes in infection status were observed during the experiment.

\section{Infection frequency}

We screened 250 field collected individual mites from five populations for infection with Wolbachia and/or Cardinium (Table 1). DNA was extracted from single mites using the cetyltrimethylammonium bromide (CTAB) extraction method as described previously (Ros and Breeuwer, 2007). Presence of Wolbachia was detected using PCR amplification of wsp and gltA. Presence of Cardinium was detected using PCR amplification of a part of the 16S rDNA and $g y r B$. Ws $p$ was amplified using the primers $w s p-81 \mathrm{~F}$ and $w s p-691 \mathrm{R}$ (Braig et al., 1998), and gltA using the primers gltA-F 5'-GAYCATGARCAR AAYGCTTCTAC-3' and gltA-R 5'-CCHGARTAAAAAT CAACRTTDGG-3', designed from available Wolbachia and Rickettsia genome sequences (Andersson et al., 1998; McLeod et al., 2004; Wu et al., 2004), and tested on isolates representative of Wolbachia supergroups A and B. Cardinium 16S rDNA was amplified using the primers CLOf and CLOr1 (Weeks et al., 2003). GyrB was amplified using primers from Groot and Breeuwer (2006).

PCR amplifications were performed in $25 \mu 1$ reactions containing $2.5 \mu \mathrm{l} 10 \times$ Super Taq buffer (HT BioTechnology, Cambridge, UK), $1.25 \mu \mathrm{l}$ bovine serum albumin $\left(10 \mathrm{mg} \mathrm{ml}^{-1}\right), 1.25 \mu \mathrm{l} \mathrm{MgCl}{ }_{2}(25 \mathrm{mM}), 5 \mu \mathrm{dNTP} \operatorname{mix}(1 \mathrm{mM}$ of each nucleotide), $0.2 \mu \mathrm{l}$ of each primer ( $20 \mu \mathrm{M}$ each), $0.2 \mu \mathrm{l}$ of super Taq ( $5 \mathrm{U}_{\mu 1}^{-1}$; HT BioTechnology), $11.9 \mu \mathrm{l}$ water and $2.5 \mu \mathrm{l}$ of DNA extract. For $16 \mathrm{~S}$ rDNA, no $\mathrm{MgCl}_{2}$ and bovine serum albumin were added. PCR cycling profile for $w s p$ was 35 cycles of $30 \mathrm{~s}$ at $95^{\circ} \mathrm{C}, 30 \mathrm{~s}$ at $51{ }^{\circ} \mathrm{C}$ and $1 \mathrm{~min}$ at $72{ }^{\circ} \mathrm{C}$; for Cardinium 16S rDNA, it was 35 cycles of $40 \mathrm{~s}$ at $95^{\circ} \mathrm{C}, 40 \mathrm{~s}$ at $57^{\circ} \mathrm{C}$ and $45 \mathrm{~s}$ at $72{ }^{\circ} \mathrm{C}$; and for glt $A$ and $g y r B$, it was 35 cycles of $1 \mathrm{~min}$ at $95^{\circ} \mathrm{C}, 1 \mathrm{~min}$ at $50^{\circ} \mathrm{C}$ and $1 \mathrm{~min}$ at $72{ }^{\circ} \mathrm{C}$. Products $(2 \mu \mathrm{l})$ were visualized on a $1 \%$ agarose gel stained with ethidium bromide in $0.5 \times$ TBE buffer $(45 \mathrm{mM}$ Tris base, $45 \mathrm{mM}$ boric acid and $1 \mathrm{mM}$ EDTA, $\mathrm{pH} 8.0$ ).

PCR amplification of a part of the mitochondrial COI gene was used as a positive control for the DNA extraction. PCR was performed as described in Ros and Breeuwer (2007) with the primers COI_F3 (5'-WGTHTTAGCAGGAGCAATTACWAT-3'; modified from Toda et al., 2000) and COI_R2 (5'-AAWCCTCTAA AAATRGCRAATACRGC-3'; modified from Hinomoto and Takafuji, 2001). Samples for which amplification of COI failed were excluded from the dataset. 
Single infections

\begin{tabular}{|c|c|}
\hline $\begin{array}{ll}\text { Does } & \text { Wolbachia cause } \mathrm{Cl} ? \\
\mathrm{U} \times \mathrm{U} & \text { control } \\
\mathrm{U} \times \mathrm{I}_{\mathrm{W}} & \mathrm{Cl} ? \\
\mathrm{I}_{\mathrm{W}} \times \mathrm{U} & \text { control } \\
\mathrm{I}_{\mathrm{W}} \times \mathrm{I}_{\mathrm{W}} & \text { control }\end{array}$ & $\begin{array}{ll}\text { Does } & \text { Cardinium } \\
\mathrm{U} \times \mathrm{U} & \text { control } \\
\mathrm{U} \times \mathrm{I}_{\mathrm{C}} & \mathrm{Cl} ? \\
\mathrm{I}_{\mathrm{C}} \times \mathrm{U} & \text { control } \\
\mathrm{I}_{\mathrm{C}} \times \mathrm{I}_{\mathrm{C}} & \text { control }\end{array}$ \\
\hline Interactions & When $\mathrm{Cl}$ is induced: \\
\hline $\begin{array}{ll}\text { Is } \mathrm{Cl} \text { expressed in doubly infected } \\
\text { individuals? } \\
\mathrm{U} \times \mathrm{U} & \text { control } \\
\mathrm{U} \times \mathrm{I}_{\mathrm{WC}} & \mathrm{Cl} ? \\
\mathrm{I}_{\mathrm{WC}} \times U & \text { control } \\
\mathrm{I}_{\mathrm{WC}} \times \mathrm{I}_{\mathrm{WC}} & \text { control }\end{array}$ & 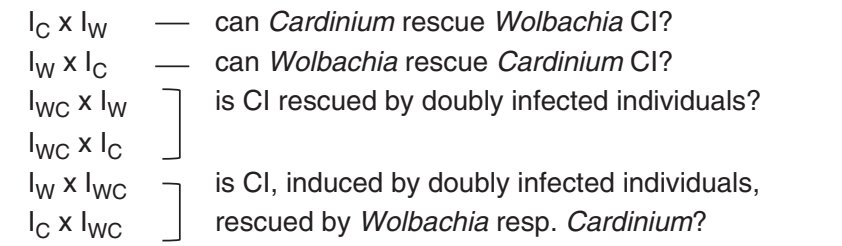 \\
\hline
\end{tabular}

Figure 1 Overview of research questions and associated crossing schemes needed to determine the role of Wolbachia and Cardinium in cytoplasmic incompatibility (CI) induction in singly and doubly infected host individuals.

Table 1 Origin of Bryobia sarothamni populations included in this study, and the name and infection status of IF lines that were used in the crossing experiments

\begin{tabular}{|c|c|c|c|c|c|}
\hline Population & Country & Locality & Collection date & IF & Infection \\
\hline BEL5 & Belgium & Vierves sur Viroin & July 2006 & $\begin{array}{l}\text { BEL5_2 } \\
\text { BEL5 3 }\end{array}$ & $\begin{array}{c}I_{\mathrm{W}} \\
\mathrm{U}\end{array}$ \\
\hline BEL6 & Belgium & Vierves sur Viroin & July 2006 & & \\
\hline FR16 & France & Vireux & July 2006 & $\begin{array}{l}\text { FR16_1 } \\
\text { FR16 2 } \\
\text { FR16 } 3 \\
\text { FR16 } 4 \\
\text { FR16 } 6 \\
\text { FR16 } 7 \\
\text { FR16 } 8\end{array}$ & $\begin{array}{c}I_{\mathrm{W}} \\
I_{\mathrm{WC}} \\
I_{\mathrm{W}} \\
I_{\mathrm{WC}} \\
\mathrm{U} \\
I_{\mathrm{WC}} \\
I_{\mathrm{W}}\end{array}$ \\
\hline $\begin{array}{l}\text { FR21 } \\
\text { NI 17 }\end{array}$ & France & Piriac sur mer & Aug 2006 & FR21_2 & $I_{\mathrm{C}}$ \\
\hline NL17 & Netherlands & Schoorl & Aug 2006 & & \\
\hline
\end{tabular}

Abbreviations: $\mathrm{U}$, uninfected; IF, isofemale; $I_{\mathrm{C}}$, Cardinium-infected; $I_{\mathrm{W}}$, Wolbachia-infected; $I_{\mathrm{WC}}$, doubly infected (Wolbachia and Cardinium). ${ }^{a}$ This IF line was used for 16S amplification and cloning, but was not included in the crossing experiments. Population BEL6 and NL17 were included in the assessment of infection frequencies, but not in the crossing experiments.

\section{Screening for other reproductive parasites}

To test for multiple infections by other bacteria, we amplified and cloned the $16 \mathrm{~S}$ rDNA gene for five pooled individuals per isofemale line (one of each infection status). DNA was extracted following the CTAB method (Ros and Breeuwer, 2007). 16S rDNA was amplified using the primers 27F 5'-AGAGTTTGATCMTGGCTC AG-3' and 1513R 5'-ACGGYTACCTTGTTACGACTT-3' (Weisburg et al., 1991) in a $25 \mu \mathrm{l}$ reaction mix containing $2.5 \mu \mathrm{l}$ of $10 \times$ Super Taq buffer, $5 \mu \mathrm{l}$ dNTP mix $(1 \mathrm{mM}$ of each nucleotide), $0.5 \mu \mathrm{l}$ of each primer ( $10 \mu \mathrm{M}$ each), $0.2 \mu \mathrm{l}$ of super Taq $\left(5 \mathrm{U}^{-1}\right), 13.3 \mu \mathrm{l}$ water and $3 \mu \mathrm{l}$ of DNA extract. PCR cycling profile was 35 cycles of $1 \mathrm{~min}$ at $94{ }^{\circ} \mathrm{C}, 1 \mathrm{~min}$ at $54{ }^{\circ} \mathrm{C}$ and $1 \mathrm{~min}$ at $72^{\circ} \mathrm{C}$. PCR products were cleaned using the method of Boom et al. (1990). The cleaned products were ligated and bacteria were transformed using the pGEM-T Easy Vector System and JM109 competent cells (Promega, Madison WI, USA). 10-11 clones were sequenced per sample, using the M13 forward primer. The sequence of each clone was compared to sequences present in GenBank using BLAST (www.ncbi.nlm.nih.gov/blast).

\section{Crossing experiment}

The effects of Wolbachia and/or Cardinium on host reproduction were established by combining doubly infected, singly infected and uninfected mites (see Figure 1 for crosses and their possible effects). For the crossing experiments, mites were used from nine isofemale lines that were started from naturally infected (singly or doubly) and uninfected mites collected from three populations (Table 1). Infection status of each line was assessed by screening individual females as described above. For each possible infection status $\left(I_{\mathrm{WC}}, I_{\mathrm{W}}, I_{\mathrm{C}}\right.$ and $\left.U\right), 1-4$ isofemale lines were used (Table 1). Age cohorts were produced for each of these selected lines, by groups of females laying eggs for 1-2 
days on C. scoparius branches. Offspring of these cohorts were used in crossing experiments. Ideally, antibiotic cured isofemale lines should be used to account for host background effects. However, antibiotic treatments with tetracycline or doxycycline of doubly infected females were so far unsuccessful in creating all other types of infection among the offspring. Therefore, we used naturally infected and uninfected lines. Mites were collected as (virgin) teleiochrysalids (last resting stage before the adult reproductive phase). Pupae were placed individually on filter paper in petridishes covered with parafilm, and checked daily for emergence. Upon emergence, pairs of one female and one male were formed and placed on a single $C$. scoparius branch. Adult males and females were maximum 1 day old, except for four cases where males were 2 days old. Males were removed after $24 \mathrm{~h}$. Males were only used once, except for two cases where males mated twice. Females were removed after 10 days (which generally means 8 days of egg laying; the first 2 days after emergence no eggs are produced). The number of eggs, unhatched eggs, emerging adult offspring (sons and daughters) and mortality (dead stages excluding eggs) were scored per cross.

\section{Fitness effects}

The fitness costs of infection with Wolbachia, Cardinium, or both, were assessed by comparing the fecundity of females with the four possible infection types. We compared crosses in which females were crossed with uninfected males to exclude any influence of differences in male fertility due to infection.

\section{Statistical analyses}

Groups of crosses were tested for differences in investigated traits using the software package SPSS version 15.0 (Chicago, IL, USA). Tests were performed for individual bacterial effects, and for interactions between Wolbachia and Cardinium (Table 2). Data were first tested for normality (Kolmogorov-Smirnov test) and homogeneity of group variances (Levene's test). Where possible, square-root, logarithmic or arcsine transformations were performed to attain normality and homogeneity of variances. A one-way analysis of variance was performed for each trait (number of eggs laid, unhatched eggs, sex ratio (\% males), number of offspring, number of sons, number of daughters and mortality) separately to determine whether there was heterogeneity among different crosses with respect to each trait. If heterogeneity was significant, pairwise comparisons were performed using Tukey post hoc tests. Additional nonparametric tests (Kruskal-Wallis) were used when analysis of variance assumptions on normality and homogeneity of variances were violated and could not be met by data transformations. Crosses in which fewer than nine eggs were laid were excluded from CI analyses. We excluded cases where all male offspring in combination with normal clutch size, high egg hatchability and low juvenile mortality (that is, number of unhatched eggs and dead stages was less than four) was recorded, as it is most likely due to females not having mated. Differences in fecundity between each of the four infection types were determined using the same statistical approach as outlined above.

\section{Results}

Infection frequency

We screened 250 individual mites, collected form five field populations, for infection with Wolbachia and/or Cardinium (Figure 2). Four populations appeared to be infected-two with both Cardinium and Wolbachia and two with Wolbachia only. Only the population from the Netherlands (NL17) was uninfected. Population FR16 is polymorphic for infection with Wolbachia as well as Cardinium - 59\% of the individuals harbor both Wolbachia and Cardinium, 36\% is only infected with Wolbachia, 2\% only with Cardinium, and 3\% is uninfected. Populations BEL5 and BEL6 are closely located to FR16, but harbor only Wolbachia and no Cardinium-53\% (BEL5) and 73\% (BEL6) of the individuals are Wolbachia-infected. The more distantly located population FR21 shows a high frequency of doubly infected individuals (89\%) and no singly infected individuals; however, only nine individuals were screened for this population.

\section{Screening for other reproductive parasites}

We screened four isofemale lines (one of each infection status) for infections with other bacteria. Cloning of $16 S$ rDNA shows that strain FR16_1 is infected with Wolbachia only, as no double infections with other bacteria are found. The ten clones sequenced show minimal sequence differences $(<1 \%)$. Differences were randomly distributed across first, second and third codon positions, and in some cases lead to stop codons or amino-acid changes. It is, therefore, likely that these differences are sequence artifacts, and do not concern multiple infections. For B. sarothamni strain FR21_2, all clones were Cardinium sequences, except one clone, which was identified as Ochrobactrum spec. ( $\alpha$-Proteobacteria). Ochrobactrum has been described from nodules of C. scoparius (Zurdo-Pineiro et al., 2007), which is the host plant of $B$. sarothamni. This clone was considered as contamination and discarded. Within B. sarothamni strain FR16_2 both Wolbachia (eight clones) and Cardinium (two clones) were detected. This confirms the double infection found by PCR amplification. Within B. sarothamni strain FR16_6 neither Wolbachia nor Cardinium were detected, confirming earlier PCR results. No other reproductive parasites, such as Rickettsia or Spiroplasma, previously shown to be common in spiders (Goodacre et al., 2006), were detected in any of the cloned samples. The sequences found most likely represent general contaminant bacteria-six clones were similar to Streptococcus spp. (human oral clones), two to the family Flavobacteriaceae (human oral clones), one to a soil bacterium (family Xanthomonadaceae) and one to an unidentified human oral bacterium.

\section{Crossing experiments}

Individual bacterial effects: The number of aborted eggs was significantly different among the four crosses in which the effect of Cardinium was investigated (Table 2a). In the predicted incompatible cross $\left(U \times I_{C}\right.$; Figure 1$)$, on average, $56.9 \%$ of all eggs did not hatch, against $3.6-10.2 \%$ in the other crosses. The sex ratio of the offspring that did hatch in the incompatible cross approached $100 \%$; only in one of the crosses, a single female was produced. Related to the large number of 
Table 2 Results of crosses between $\mathrm{U}, I_{\mathrm{C}}, I_{\mathrm{W}}$ and $I_{\mathrm{WC}}$ Bryobia sarothamni strains

\begin{tabular}{|c|c|c|c|c|c|c|c|c|c|}
\hline Effect & Cross $F \times M$ & $\mathrm{~N}$ & Number of eggs & $\%$ Unhatched eggs & Sex ratio ( $\%$ males) & Sons & Daughters & Total offspring & $\begin{array}{l}\text { \% Mortality } \\
\text { (excl. eggs) }\end{array}$ \\
\hline \multicolumn{10}{|l|}{ (a) } \\
\hline \multirow[t]{5}{*}{ Single effect: Cardinium CI? } & $\mathrm{U} \times \mathrm{U}$ & 20 & $20.0 \pm 1.3$ & $3.6 \pm 1.0^{\mathrm{a}}$ & $39.1 \pm 4.0^{\mathrm{a}}$ & $5.5 \pm 0.8$ & $8.3 \pm 1.1^{\mathrm{a}}$ & $13.8 \pm 1.6^{\mathrm{a}}$ & $10.4 \pm 2.4$ \\
\hline & $\mathrm{U} \times I_{\mathrm{C}}$ & 16 & $19.1 \pm 1.3$ & $56.9 \pm 4.4^{\mathrm{b}}$ & $96.9 \pm 3.1^{\mathrm{b}}$ & $3.9 \pm 0.5$ & $0.1 \pm 0.1^{\mathrm{b}}$ & $3.9 \pm 0.5^{\mathrm{b}}$ & $3.0 \pm 0.8$ \\
\hline & $I_{C} \times U$ & 17 & $16.6 \pm 0.8$ & $10.2 \pm 2.3^{\mathrm{a}}$ & $48.8 \pm 5.9^{\mathrm{a}, \mathrm{c}}$ & $4.7 \pm 0.7$ & $5.0 \pm 0.8^{c}$ & $9.7 \pm 0.8^{\mathrm{a}}$ & $4.6 \pm 1.0$ \\
\hline & $I_{\mathrm{C}} \times I_{\mathrm{C}}$ & 19 & $17.5 \pm 0.8$ & $4.9 \pm 1.1^{\mathrm{a}}$ & $56.9 \pm 3.6^{c}$ & $5.4 \pm 0.6$ & $4.3 \pm 0.6^{c}$ & $9.7 \pm 1.0^{\mathrm{a}}$ & $10.3 \pm 3.0$ \\
\hline & & & NS & $* * *$ & $* * *$ & NS & $* * *$ & $* * *$ & NS \\
\hline \multicolumn{10}{|l|}{ (b) } \\
\hline \multirow[t]{5}{*}{ Single effect: Wolbachia CI? } & $\mathrm{U} \times \mathrm{U}$ & 20 & $20.0 \pm 1.3$ & $3.6 \pm 1.0^{\mathrm{a}, \mathrm{b}}$ & $39.1 \pm 4.0$ & $5.5 \pm 0.8$ & $8.3 \pm 1.1$ & $13.8 \pm 1.6$ & $10.4 \pm 2.4$ \\
\hline & $\mathrm{U} \times I_{\mathrm{W}}$ & 15 & $21.5 \pm 1.5$ & $8.6 \pm 2.0^{\mathrm{a}, \mathrm{b}}$ & $44.2 \pm 4.1$ & $6.3 \pm 0.8$ & $8.5 \pm 1.1$ & $14.7 \pm 1.4$ & $5.1 \pm 1.5$ \\
\hline & $I_{\mathrm{W}} \times \mathrm{U}$ & 16 & $17.7 \pm 1.0$ & $10.6 \pm 3.5^{\mathrm{b}}$ & $38.6 \pm 6.0$ & $3.4 \pm 0.7$ & $6.3 \pm 1.0$ & $9.6 \pm 1.2$ & $8.4 \pm 2$ \\
\hline & $I_{\mathrm{W}} \times I_{\mathrm{W}}$ & 14 & $17.2 \pm 1.5$ & $1.6 \pm 1.3^{\mathrm{a}}$ & $33.7 \pm 4.8$ & $3.9 \pm 0.9$ & $6.6 \pm 1.1$ & $10.4 \pm 1.7$ & $8.6 \pm 2.6$ \\
\hline & & & NS & $* *$ & NS & NS & NS & NS & NS \\
\hline \multicolumn{10}{|l|}{ (c) } \\
\hline \multirow[t]{5}{*}{ Interaction: double infection $\mathrm{CI}$ ? } & $\mathrm{U} \times \mathrm{U}$ & 20 & $20.0 \pm 1.3$ & $3.6 \pm 1.0$ & $39.1 \pm 4.0$ & $5.5 \pm 0.8$ & $8.3 \pm 1.1$ & $13.8 \pm 1.6$ & $10.4 \pm 2.4$ \\
\hline & $\mathrm{U} \times I_{\mathrm{WC}}$ & 18 & $21.7 \pm 1.7$ & $15.5 \pm 5.3$ & $50.9 \pm 6.5$ & $6.6 \pm 1.2$ & $6.9 \pm 1.3$ & $13.4 \pm 2.1$ & $6.7 \pm 3.7$ \\
\hline & $I_{\mathrm{wc}} \times \mathrm{U}$ & 11 & $22.4 \pm 1.5$ & $4.4 \pm 1.4$ & $28.7 \pm 6.5$ & $4.4 \pm 1.4$ & $11.3 \pm 1.7$ & $15.6 \pm 1.7$ & $5.9 \pm 2.5$ \\
\hline & $I_{\mathrm{wc}} \times I_{\mathrm{WC}}$ & 9 & $21.8 \pm 1.4$ & $2.3 \pm 1.1$ & $33.8 \pm 7.1$ & $6.0 \pm 1.4$ & $11.7 \pm 1.6$ & $17.7 \pm 1.3$ & $5.0 \pm 2.5$ \\
\hline & & & NS & NS & NS & NS & NS & NS & NS \\
\hline \multicolumn{10}{|l|}{ (d) } \\
\hline \multirow[t]{5}{*}{ Interaction: Cardinium $\mathrm{CI}$ rescued? } & $\mathrm{U} \times I_{\mathrm{C}}$ & 16 & $19.1 \pm 1.3$ & $56.9 \pm 4.4^{\mathrm{a}}$ & $96.9 \pm 3.1^{\mathrm{a}}$ & $3.9 \pm 0.5^{\mathrm{a}, \mathrm{b}}$ & $0.1 \pm 0.1^{\mathrm{a}}$ & $3.9 \pm 0.5^{\mathrm{a}}$ & $3.0 \pm 0.8$ \\
\hline & $I_{\mathrm{C}} \times I_{\mathrm{C}}$ & 19 & $17.5 \pm 0.8$ & $4.9 \pm 1.1^{\mathrm{b}}$ & $56.9 \pm 3.6^{\mathrm{b}}$ & $5.4 \pm 0.6^{\mathrm{a}}$ & $4.3 \pm 0.6^{\mathrm{b}}$ & $9.7 \pm 1.0^{\mathrm{b}}$ & $10.3 \pm 3.0$ \\
\hline & $I_{\mathrm{W}} \times I_{\mathrm{C}}$ & 12 & $15.6 \pm 1.2$ & $50.6 \pm 6.8^{\mathrm{a}}$ & $100.0 \pm 0.0^{\mathrm{a}}$ & $3.2 \pm 0.8^{\mathrm{a}, \mathrm{b}}$ & $0.0 \pm 0.0^{\mathrm{a}}$ & $3.2 \pm 0.8^{\mathrm{a}}$ & $7.5 \pm 2.5$ \\
\hline & $I_{\mathrm{WC}} \times I_{\mathrm{C}}$ & 12 & $17.0 \pm 1.0$ & $67.2 \pm 5.7^{\mathrm{a}}$ & $100.0 \pm 0.0^{\mathrm{a}}$ & $2.4 \pm 0.6^{\mathrm{b}}$ & $0.0 \pm 0.0^{\mathrm{a}}$ & $2.4 \pm 0.6^{\mathrm{a}}$ & $2.3 \pm 1.0$ \\
\hline & & & NS & $* * *$ & $* * *$ & $* *$ & $* * *$ & $* * *$ & NS \\
\hline \multicolumn{10}{|l|}{$(e)$} \\
\hline \multirow[t]{5}{*}{ Interaction: remaining crosses } & $\mathrm{U} \times I_{\mathrm{W}}$ & 15 & $21.5 \pm 1.5$ & $8.6 \pm 1.8^{\mathrm{a}}$ & $44.2 \pm 5.1^{\mathrm{a}, \mathrm{b}}$ & $6.3 \pm 0.9$ & $8.5 \pm 1.1$ & $14.7 \pm 1.5$ & $5.1 \pm 2.9$ \\
\hline & $I_{\mathrm{C}} \times I_{\mathrm{W}}$ & 16 & $17.9 \pm 1.4$ & $10.5 \pm 1.8^{\mathrm{a}}$ & $58.2 \pm 4.9^{\mathrm{a}}$ & $6.8 \pm 0.9$ & $4.6 \pm 1.0$ & $11.3 \pm 1.5$ & $6.5 \pm 2.8$ \\
\hline & $I_{\mathrm{W}} \times I_{\mathrm{W}}$ & 14 & $17.1 \pm 1.5$ & $1.6 \pm 1.9^{\mathrm{b}}$ & $33.7 \pm 5.3^{\mathrm{b}}$ & $3.9 \pm 1.0$ & $6.6 \pm 1.1$ & $10.4 \pm 1.6$ & $8.6 \pm 3.0$ \\
\hline & $I_{\mathrm{WC}} \times I_{\mathrm{W}}$ & 16 & $17.6 \pm 1.4$ & $4.5 \pm 1.8^{\mathrm{a}, \mathrm{b}}$ & $34.7 \pm 4.9^{\mathrm{b}}$ & $4.6 \pm 0.9$ & $8.0 \pm 1.0$ & $12.6 \pm 1.5$ & $11.1 \pm 2.8$ \\
\hline & & & NS & $* *$ & $* *$ & NS & $*$ & NS & NS \\
\hline \multirow{6}{*}{$\begin{array}{l}\text { (f) } \\
\text { Interaction: remaining crosses }\end{array}$} & & & & & & & & & \\
\hline & $\mathrm{U} \times I_{\mathrm{WC}}$ & 18 & $21.7 \pm 1.7$ & $15.5 \pm 5.3$ & $50.9 \pm 6.5$ & $6.6 \pm 1.2$ & $6.9 \pm 1.3^{\mathrm{a}, \mathrm{b}}$ & $13.4 \pm 2.1^{\mathrm{a}, \mathrm{b}}$ & $6.7 \pm 3.7$ \\
\hline & $I_{\mathrm{c}} \times I_{\mathrm{WC}}$ & 10 & $17.9 \pm 0.9$ & $11.2 \pm 3.7$ & $56.3 \pm 5.8$ & $6.3 \pm 0.8$ & $5.2 \pm 1.1^{\mathrm{a}}$ & $11.5 \pm 1.2^{\mathrm{a}, \mathrm{b}}$ & $3.7 \pm 1.1$ \\
\hline & $I_{\mathrm{w}} \times I_{\mathrm{WC}}$ & 10 & $16.2 \pm 1.6$ & $6.6 \pm 1.5$ & $46.4 \pm 5.6$ & $4.3 \pm 0.8$ & $5.0 \pm 1.1^{\mathrm{a}}$ & $9.3 \pm 1.6^{\mathrm{a}}$ & $12.9 \pm 3.0$ \\
\hline & $I_{\mathrm{wc}} \times I_{\mathrm{WC}}$ & 9 & $21.8 \pm 1.4$ & $2.3 \pm 1.1$ & $33.8 \pm 7.1$ & $6.0 \pm 1.4$ & $11.7 \pm 1.6^{\mathrm{b}}$ & $17.7 \pm 1.3^{\mathrm{b}}$ & $5.0 \pm 2.5$ \\
\hline & & & NS & NS & NS & NS & ** & 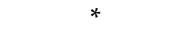 & NS \\
\hline
\end{tabular}

Abbreviations: $I_{\mathrm{C}}$, Cardinium-infected; $I_{\mathrm{W}}$, Wolbachia-infected; $I_{\mathrm{WC}}$, doubly infected (Wolbachia and Cardinium); N, number of replicates; NS, not significant; $\mathrm{U}$, uninfected. Rows a-f contain

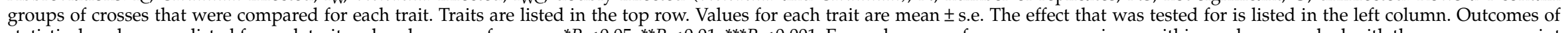

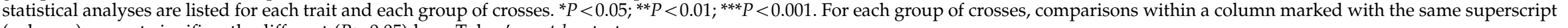
$(\mathrm{a}, \mathrm{b}$ or $\mathrm{c})$ are not significantly different $(P>0.05)$ by a Tukey's post hoc test. 


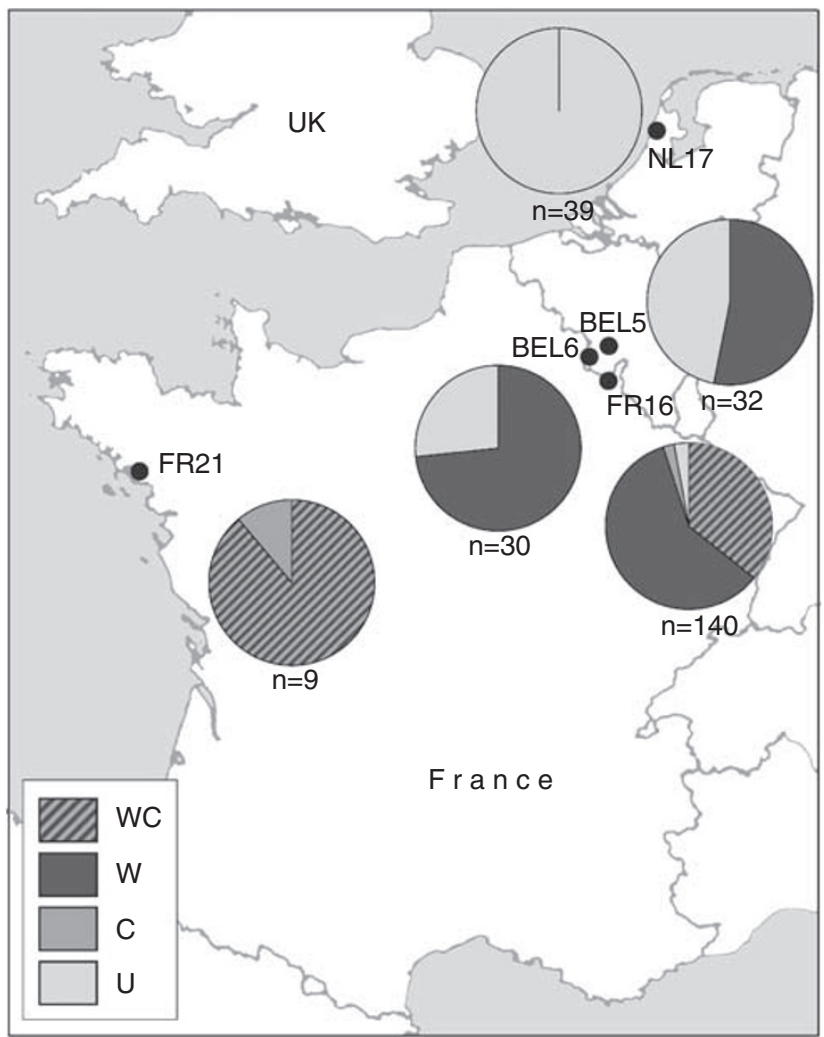

Figure 2 Infection frequencies of uninfected, singly infected (Wolbachia or Cardinium) and doubly infected (Wolbachia and Cardinium) individuals of Bryobia sarothamni in five European populations. $n=$ sample size.

aborted eggs, the total number of offspring was also significantly lower in the incompatible cross. This was because of a decrease in the number of females produced, as the number of males produced, was not significantly different between the four crosses. The number of eggs produced and the mortality (of nonegg stages) were not significantly different among the four crosses.

Among the four crosses in which we tested possible Wolbachia CI effects, no significant differences were found between the predicted incompatible cross and the other crosses for any of the investigated traits (Table 2b). A significant difference in the number of aborted eggs was found between crosses $I_{\mathrm{W}} \times \mathrm{U}$ and $I_{\mathrm{W}} \times I_{\mathrm{W}}$. The low number of aborted eggs in the $I_{\mathrm{W}} \times I_{\mathrm{W}}$ cross was, however, likely due to a problem with the experimental setup. In the $I_{\mathrm{W}} \times I_{\mathrm{W}}$ cross, a high number of eggs were drowned (these eggs were not included in the computation of the number of aborted eggs).

\section{Interactions between Wolbachia and Cardinium}

Doubly infected males $\left(I_{\mathrm{WC}}\right)$ did not induce CI (Table 2c). No significant effects were found for any of the investigated traits for the four crosses. The average number of aborted eggs was higher in the predicted incompatible cross $\left(\mathrm{U} \times \mathrm{I}_{\mathrm{C}}\right)$, but it is not significantly different from the other three crosses.

Concluding from the results in Table $2 a-c$, it is believed that singly infected Cardinium individuals induce strong CI, whetreas singly infected Wolbachia or doubly infected individuals do not induce CI. We compared all possible crosses involving singly infected Cardinium males to investigate in which crosses the induced CI was rescued. As is apparent from Table 2d, Cardinium-induced CI is only rescued in crosses with Cardinium-infected females. Crosses involving uninfected, Wolbachia-infected or doubly infected females all show strong CI expressed in a reduced egg hatchability and a male-biased sex ratio. Therefore, CI induced by Cardinium is neither rescued by Wolbachia nor by doubly infected individuals.

We also investigated other possible crosses, involving Wolbachia-infected males (Table 2e) and doubly infected males (Table 2f). Among the four crosses involving Wolbachia-infected males, a significant difference in the number of aborted eggs and in the sex ratio was found; the cross between Wolbachia-infected females and males $\left(I_{\mathrm{W}} \times I_{\mathrm{W}}\right)$ had a lower number of aborted eggs than the three other crosses $\left(\mathrm{U} \times I_{\mathrm{W}}, I_{\mathrm{C}} \times I_{\mathrm{W}}\right.$ and $\left.I_{\mathrm{WC}} \times I_{\mathrm{W}}\right)$. The number is, however, also lower than that found in many other crosses, and might be due to the fact that a high number of eggs was lost in this cross due to a problem with the experimental setup (a number of eggs got wet; see above). The sex ratio in the $I_{\mathrm{C}} \times I_{\mathrm{W}}$ cross was higher than in the $I_{\mathrm{W}} \times I_{\mathrm{W}}$ and $I_{\mathrm{WC}} \times I_{\mathrm{WC}}$ crosses, but not higher than the $\mathrm{U} \times I_{\mathrm{W}}$ cross.

\section{Fitness effects}

We measured fitness costs of infection by comparing the fecundity of singly, doubly and uninfected females. Egg production was the highest in doubly infected females, and significantly higher than the egg production of singly (Wolbachia or Cardinium) infected females (Table 3). It was not significantly different from the egg production of uninfected females. The same pattern was observed for the number of daughters, and therefore also for the total number of offspring produced. The remaining traits were not significantly different between the four crosses.

When all crosses are included in the analysis (that is, including crosses with singly and doubly infected males), the differences in egg production are less obvious (Table 3). The number of eggs produced by doubly infected females was not significantly different from females of any of the other infection types. This is mainly due to the fact that fewer eggs were produced in crosses between doubly infected individuals and either singly Cardinium-, or singly Wolbachia-infected males (Table 2). The number of eggs produced by singly infected lines was significantly lower than the number produced by uninfected lines.

\section{Discussion}

Cardinium causes severe $\mathrm{CI}$ in the sexual spider mite B. sarothamni. CI is expressed as a strong reduction in egg hatchability and a strongly male-biased sex ratio in crosses between uninfected females and infected males. The CI expression is nearly complete: only one daughter was produced in all incompatible crosses, whereas male production was not significantly different from the compatible crosses. The observed pattern suggests that fertilized eggs, which would normally develop into females, suffer from mortality. This is concordant with the female mortality type of CI (Breeuwer, 1997; Vavre 
Table 3 Fitness of $\mathrm{U}, I_{\mathrm{C}}, I_{\mathrm{W}}$ and $I_{\mathrm{WC}}$ Bryobia sarothamni strains

\begin{tabular}{|c|c|c|c|c|c|c|c|c|c|c|c|}
\hline \multirow[b]{2}{*}{ Cross $F \times M$} & \multicolumn{8}{|c|}{ Crossings with uninfected males } & \multicolumn{3}{|c|}{ All crossings } \\
\hline & $N$ & $\begin{array}{c}\text { Number of } \\
\text { eggs }\end{array}$ & $\begin{array}{c}\text { \% Unhatched } \\
\text { eggs }\end{array}$ & $\begin{array}{l}\text { Sex ratio } \\
(\% \text { males })\end{array}$ & Sons & Daughters & $\begin{array}{c}\text { Total } \\
\text { offspring }\end{array}$ & $\begin{array}{l}\% \text { Mortality } \\
\text { (excl eggs) }\end{array}$ & Inf. & $N$ & $\begin{array}{c}\text { Nr. of } \\
\text { eggs }\end{array}$ \\
\hline $\mathrm{U} \times \mathrm{U}$ & 20 & $20.0 \pm 1.3^{\mathrm{a}, \mathrm{b}}$ & $3.6 \pm 1.0$ & $39.1 \pm 4.0$ & $5.5 \pm 0.8$ & $8.3 \pm 1.1^{\mathrm{a}, \mathrm{b}}$ & $13.8 \pm 1.6^{\mathrm{a}, \mathrm{b}}$ & $10.4 \pm 2.4$ & $\mathrm{U}$ & 75 & $20.0 \pm 0.7^{\mathrm{b}}$ \\
\hline $\mathrm{I}_{\mathrm{C}} \times \mathrm{U}$ & 17 & $16.6 \pm 0.8^{a}$ & $10.2 \pm 2.3$ & $48.8 \pm 5.9$ & $4.7 \pm 0.7$ & $5.0 \pm 0.8^{\mathrm{a}}$ & $9.7 \pm 0.8^{\mathrm{a}}$ & $4.6 \pm 1.0$ & $I_{\mathrm{C}}$ & 64 & $16.2 \pm 0.7^{\mathrm{a}}$ \\
\hline$I_{\mathrm{W}} \times \mathrm{U}$ & 16 & $17.7 \pm 1.0^{\mathrm{a}}$ & $10.6 \pm 3.5$ & $38.6 \pm 6.0$ & $3.4 \pm 0.7$ & $6.3 \pm 1.0^{\mathrm{a}}$ & $9.6 \pm 1.2^{\mathrm{a}}$ & $8.4 \pm 2.0$ & $I_{\mathrm{W}}$ & 68 & $16.7 \pm 0.4^{\mathrm{a}}$ \\
\hline$I_{\mathrm{WC}} \times \mathrm{U}$ & 11 & $\frac{22.4 \pm 1.5^{b}}{* *}$ & $\begin{array}{l}4.4 \pm 1.4 \\
\mathrm{NS}\end{array}$ & $\begin{array}{c}28.7 \pm 6.5 \\
\text { NS }\end{array}$ & $\begin{array}{c}4.4 \pm 1.4 \\
\mathrm{NS}\end{array}$ & $11.3 \pm{ }_{* *} 1.7^{\mathrm{b}}$ & $\begin{array}{c}15.6 \pm 1.7^{\mathrm{b}} \\
*\end{array}$ & $\begin{array}{l}5.9 \pm 2.5 \\
\text { NS }\end{array}$ & $I_{\mathrm{WC}}$ & 60 & $\begin{array}{c}17.9 \pm 0.7^{\mathrm{a}, \mathrm{b}} \\
* *\end{array}$ \\
\hline
\end{tabular}

Abbreviations: $I_{\mathrm{C}}$, Cardinium-infected; $I_{\mathrm{W}}$, Wolbachia-infected; $I_{\mathrm{WC}}$, doubly infected (Wolbachia and Cardinium); $\mathrm{N}$, number of replicates; NS, not significant; $\mathrm{U}$, uninfected.

Traits are listed in the top row. Values for each trait are mean \pm s.e. Outcomes of statistical analyses are listed for each trait and each group of crosses. ${ }^{*} P<0.05 ;{ }^{* *} P<0.01$. For each group of crosses, comparisons within a column marked with the same superscript (a or b) are not significantly different $(P>0.05)$ by a Tukey's post hoc test.

et al., 2000; Bordenstein et al., 2003; Mouton et al., 2005). $B$. sarothamni is the third host species in which Cardiniuminduced $\mathrm{CI}$ is observed, and this study reveals the strongest CI effect found for Cardinium so far. The other two studies on Cardinium CI found incomplete CI expression; in the parasitoid wasp E. pergandiella, $87 \%$ fewer daughters were produced in incompatible crosses, and in the spider mite E. suginamensis, this was $46 \%$ (Hunter et al., 2003; Gotoh et al., 2006). Female mortality is the only CI type found for Cardinium so far (Hunter et al., 2003; Gotoh et al., 2006). It is also the most common type of CI expression observed for Wolbachia in haplodiploid species (Breeuwer, 1997; Vala et al., 2000; Vavre et al., 2000; Mouton et al., 2005). The second CI type that has been observed in haplodiploid species is the male development type, which is expressed as an increased male production due to the conversion of fertilized diploid eggs into haploid eggs in early development (Breeuwer and Werren, 1993; Breeuwer, 1997; Vavre et al., 2000; Bordenstein et al., 2003; Mouton et al., 2005). Until now, this type of CI has not been observed for Cardinium.

Although we found a strong CI effect for Cardinium in B. sarothamni, no CI was induced by Wolbachia. There are several potential explanations for the absence of Wolbachia-induced CI.

Environmental factors including age of host, remating frequency or temperature may influence the degree of CI as they affect bacterial densities in the host (Clancy and Hoffmann, 1998; Reynolds and Hoffmann, 2002; Weeks et al., 2002). Bacterial densities are known to influence the level of CI expression (Breeuwer and Werren, 1993; Hoffmann and Turelli, 1997; Clancy and Hoffmann, 1998; Perrot-Minnot and Werren, 1999). Breeuwer and Werren (1993) showed that males of a strain with higher infection densities are incompatible with females from strains with lower bacterial densities. In our experiments, we controlled for these factors by using 1-day-old males and females, mating males only once, and performing experiments at a constant temperature. Therefore, it is unlikely that these factors are the reason for the lack of CI induction by Wolbachia.

Other factors that may influence CI expression are host genetic background or interactions between bacteria and host species (Stouthamer et al., 1999; Weeks et al., 2002). Contrasting results regarding host genetic background have been found; some studies revealed that host genetic background may account for variations in CI expression (Boyle et al., 1993; McGraw et al., 2001; Bordenstein et al., 2003), whereas others showed that the expression is independent of the host genome (Breeuwer and Werren, 1993). Other studies showed that CI may be differentially expressed in different populations of the same species, or even in individuals within a single population (Vala et al., 2000; Gotoh et al., 2007). In our experiments, we used singly Wolbachia-infected individuals from four isofemale lines from two different populations, and CI was not expressed in any of these isofemale lines, and therefore, our findings seem consistent across different host backgrounds and populations. All Wolbachiainfected (singly or doubly) strains used in our study harbored Wolbachia strains that are identical at four investigated loci (wsp, ftsZ, groEL and trmD; unpublished data). This indicates that the Wolbachia strains are at least highly related, if not completely identical.

A likely explanation for the lack of CI induction by Wolbachia-infected males is that the Wolbachia strain has the $\mathrm{mod}^{-}$phenotype that does not modify sperm (Bourtzis et al., 1998; Merçot and Poinsot, 1998; Charlat et al., 2001; Vala et al., 2002; Zabalou et al., 2004). Males infected with $\mathrm{mod}^{-}$strains are phenotypically indistinguishable from uninfected males; they are compatible with infected as well as uninfected females. Alternatively, the mod- phenotype may be indistinguishable from the effects of the absence of Wolbachia in the gonadal tissues. The presence of Wolbachia in the gonadal tissues is an important prerequisite for successful CI induction (Veneti et al., 2003). The end result, however, is the same, that is, no observable CI.

Interactions between Wolbachia and Cardinium were investigated by comparing crosses involving doubly infected individuals, and crosses between Wolbachiainfected and Cardinium-infected individuals. Doubly infected males do not induce CI, and CI induced by singly Cardinium-infected males is neither rescued by doubly infected nor by singly Wolbachia-infected females. These findings can be explained by (1) the differences in host genetic background, (2) the differences between bacterial strains, or (3) the interference between Wolbachia and Cardinium. These possibilities are explored below.

(1) As we used mites from nine naturally infected or uninfected isofemale lines obtained from three different 
populations, we could not completely control the host genetic background effects. As mentioned earlier, our findings are so far consistent across different backgrounds, but we cannot fully exclude potential impact of using mites from different populations. (2) Another explanation for the lack of CI induction in doubly infected individuals might be related to the genetic differences between the Cardinium strains in singly and doubly infected individuals. Singly and doubly infected individuals were collected from different populations (FR16 and FR21, respectively). We were unable to obtain singly and doubly infected isofemale lines from a single mite population. Ideally, one would like to generate singly infected lines from doubly infected isofemale lines to rule out confounding effects of host and bacterial genotype. Unfortunately, antibiotic treatment of doubly infected isofemales lines has so far not resulted in offspring infected with only Cardinium or Wolbachia. Genotyping of Cardinium strains from the two populations showed that they are slightly different: $0.7 \%$ difference at $16 \mathrm{~S}$ rDNA (3bp out of 407 ) and $0.8 \%$ at $g y r B$ (5bp out of 631) (unpublished data). It is possible that the modifier-rescue system of the Cardinium strain found in doubly infected individuals is different from that of the strain found in singly infected individuals, similar to the variation found for modifier-rescue systems of Wolbachia. (3) An interesting alternative explanation is that Wolbachia and Cardinium interfere in such a way, that Cardinium can neither rescue nor modify in the presence of Wolbachia. Currently, we cannot distinguish between the alternative explanations, although the second explanation seems feasible because of the differences that we found between the strains.

There are three other studies that investigated CI in individuals infected with both Wolbachia and Cardinium; Gotoh et al. (2006) detected no CI effect in the spider mite Tetranychus pueraricola, whereas Perlman et al. (2006) found a strong CI effect (increased female mortality) in the whitefly parasitoid Encarsia inaron. White et al. (2009) show that in the latter case, the CI is induced by Wolbachia, with no CI induction or rescue by Cardinium. As in the latter study, we also found an inability of the Wolbachia strain to rescue Cardinium modification; crosses between Wolbachia-infected females and Cardinium-infected males were incompatible. Apparently, these strains differ in their modifier-rescue system.

Costs related to the infection are important for determining the spread and maintenance of infections within populations (Werren, 1997; Hoffmann et al., 1998). We found a cost of infection with either Wolbachia or Cardinium; fewer eggs and daughters are produced by singly infected females compared with uninfected or doubly infected females. The latter observation that a fitness cost is imposed on singly infected individuals, but not on doubly infected individuals is surprising. This fitness advantage of doubly infected females (compared with singly infected individuals) is only apparent when these females are mated with either uninfected or doubly infected males, but not when mated to singly infected males. Apparently, the infection status also influences male fertility. Fitness effects of Wolbachia are diverse; there are several examples known where infection with Wolbachia led to decrease in fecundity of infected females (Vala et al., 2000; Perrot-Minnot et al., 2002) had no significant effect (Hoffmann et al., 1996; Poinsot and
Merçot, 1997; Bordenstein and Werren, 2000; Montenegro et al., 2006), or led to an increase in fecundity (Vavre et al., 1999; Dobson et al., 2004). In a few other arthorpods and in all nematodes, Wolbachia is obligatory, and thus required for host fertility (Bandi et al., 2001; Pannebakker et al., 2007). Cardinium is known to increase fecundity in Metaseiulus occidentalis (Weeks and Stouthamer, 2004).

Fitness costs are important determinants of infection frequencies in the field. This study is the first to compare the fitness between singly and doubly infected females, with a surprising outcome. Our finding may have implications for the persistence and spread of Wolbachia and/or Cardinium in populations. Doubly infected individuals have a higher fitness (measured as fecundity) than singly infected individuals. This observation, combined with the fact that single Cardinium infections induce CI-and therefore stimulate the spread of singly infected Cardinium individuals-may result in complex infection dynamics. We investigated infection frequency in five populations, and found two populations that were infected with both Wolbachia and Cardinium. In population FR16 (140 individuals), the majority (59\%) of individuals harbor both Wolbachia and Cardinium, and singly infected Cardinium individuals are extremely rare (2\%). In population FR21 (nine individuals), most individuals are doubly infected. These polymorphisms might be transient states, for example, as Cardinium and/ or Wolbachia recently infected the population and fixation of infection has not been reached yet. However, polymorphism may persist under certain conditions. Factors determining the infection frequencies are the level of CI induced, the costs of infection, efficiency of vertical transmission and rate of possible horizontal transmission (Werren, 1997; Hoffmann et al., 1998). Horizontal transmission allows invasion without any manipulation, and was recently suggested as a possible explanation for the invasion of Cardinium in spiders (Duron et al., 2008). Even so, a high temperature or naturally occurring antibiotics may cure individuals of infection (van Opijnen and Breeuwer, 1999). It is also unknown how densities are regulated in doubly infected individuals, and how both Wolbachia and Cardinium are faithfully transmitted to the next generation (Stouthamer et al., 1999; Perlman et al., 2006). More detailed transmission studies should answer such questions. Furthermore, other factors, such as the role of symbionts in resistance to parasitoids, may influence the frequency of symbionts in populations (Oliver et al., 2005). In most studies on CI, infection frequencies in the field have not been estimated. More detailed studies including field estimates will improve our understanding of infection dynamics and the fundamental factors determining symbiont frequencies (Weeks et al., 2002).

\section{Acknowledgements}

We thank Betsie Voetdijk and Sangeeta Jessurun for assistance with cloning and sequencing, Louis Lie for help with maintaining cultures and Jan van Arkel for help with the figures. Thanks to Molly Hunter and Steph Menken for useful discussions and valuable comments on the manuscript. We thank three anonymous reviewers for helpful suggestions. This research was funded by a grant from The Netherlands Organisation for Scientific Research (NWO; ALW4PJ/03-25). 


\section{References}

Andersson SGE, Zomorodipour A, Andersson JO, SicheritzPonten T, Alsmark UCM, Podowski RM et al. (1998). The genome sequence of Rickettsia prowazekii and the origin of mitochondria. Nature 396: 133-140.

Bandi C, Trees AJ, Brattig NW (2001). Wolbachia in filarial nematodes: evolutionary aspects and implications for the pathogenesis and treatment of filarial diseases. Vet Parasitol 98: 215-238.

Boom R, Sol CJA, Salimans MMM, Jansen CL, Wertheim-van Dillen PME, Van der Noordaa J (1990). Rapid and simple method for purification of nucleic-acids. J Clin Microbiol 28: 495-503.

Bordenstein SR, Uy JJ, Werren JH (2003). Host genotype determines cytoplasmic incompatibility type in the haplodiploid genus Nasonia. Genetics 164: 223-233.

Bordenstein SR, Werren JH (2000). Do Wolbachia influence fecundity in Nasonia vitripennis? Heredity 84: 54-62.

Bourtzis K, Dobson SL, Braig HR, O'Neill SL (1998). Rescuing Wolbachia have been overlooked... Nature 391: 852-853.

Boyle L, O'Neill SL, Robertson HM, Karr TL (1993). Interspecific and intraspecific horizontal transfer of Wolbachia in Drosophila. Science 260: 1796-1799.

Braig HR, Zhou WG, Dobson SL, O'Neill SL (1998). Cloning and characterization of a gene encoding the major surface protein of the bacterial endosymbiont Wolbachia pipientis. J Bacteriol 180: 2373-2378.

Breeuwer JAJ (1997). Wolbachia and cytoplasmic incompatibility in the spider mites Tetranychus urticae and T. turkestani. Heredity 79: 41-47.

Breeuwer JAJ, Jacobs G (1996). Wolbachia: Intracellular manipulators of mite reproduction. Exp Appl Acarol 20: 421-434.

Breeuwer JAJ, Werren JH (1990). Microorganisms associated with chromosome destruction and reproductive isolation between 2 insect species. Nature 346: 558-560.

Breeuwer JAJ, Werren JH (1993). Cytoplasmic incompatibility and bacterial density in Nasonia vitripennis. Genetics 135: 565-574.

Charlat S, Calmet C, Merçot H (2001). On the mod resc model and the evolution of Wolbachia compatibility types. Genetics 159: $1415-1422$

Clancy DJ, Hoffmann AA (1998). Environmental effects on cytoplasmic incompatibility and bacterial load in Wolbachiainfected Drosophila simulans. Entomol Exp Appl 86: 13-24.

Dobson SL, Rattanadechakul W, Marsland EJ (2004). Fitness advantage and cytoplasmic incompatibility in Wolbachia single- and superinfected Aedes albopictus. Heredity 93: 135-142.

Duron O, Hurst GDD, Hornett EA, Josling JA, Engelstadter J (2008). High incidence of the maternally inherited bacterium Cardinium in spiders. Mol Ecol 17: 1427-1437.

Goodacre SL, Martin OY, Thomas CFG, Hewitt GM (2006). Wolbachia and other endosymbiont infections in spiders. Mol Ecol 15: 517-527.

Gotoh T, Noda H, Ito S (2006). Cardinium symbionts cause cytoplasmic incompatibility in spider mites. Heredity 98: 13-20.

Gotoh T, Sugasawa J, Noda H, Kitashima Y (2007). Wolbachiainduced cytoplasmic incompatibility in Japanese populations of Tetranychus urticae (Acari: Tetranychidae). Exp Appl Acarol 42: 1-16.

Groot TVM, Breeuwer JAJ (2006). Cardinium symbionts induce haploid thelytoky in most clones of three closely related Brevipalpus species. Exp Appl Acarol 39: 257-271.

Hilgenboecker K, Hammerstein P, Schlattmann P, Telschow A, Werren JH (2008). How many species are infected with Wolbachia?-a statistical analysis of current data. FEMS Microbiol Lett 281: 215-220.

Hinomoto N, Takafuji A (2001). Genetic diversity and phylogeny of the Kanzawa spider mite, Tetranychus kanzawai, in Japan. Exp Appl Acarol 25: 355-370.
Hoffmann AA, Clancy D, Duncan J (1996). Naturally-occurring Wolbachia infection in Drosophila simulans that does not cause cytoplasmic incompatibility. Heredity 76: 1-8.

Hoffmann AA, Hercus M, Dagher H (1998). Population dynamics of the Wolbachia infection causing cytoplasmic incompatibility in Drosophila melanogaster. Genetics 148: 221-231.

Hoffmann AA, Turelli M (1997). Cytoplasmic incompatibility in insects. In: O'Neill SL, Hoffmann AA, Werren JH (eds). Influential passengers. Inherited microorganisms and arthropod reproduction. Oxford University Press: New York. pp 42-80.

Hunter MS, Perlman SJ, Kelly SE (2003). A bacterial symbiont in the Bacteroidetes induces cytoplasmic incompatibility in the parasitoid wasp Encarsia pergandiella. Proc $R$ Soc Lond B 270: 2185-2190.

Jeyaprakash A, Hoy MA (2000). Long PCR improves Wolbachia DNA amplification: wsp sequences found in $76 \%$ of sixtythree arthropod species. Insect Mol Biol 9: 393-405.

McGraw EA, Merritt DJ, Droller JN, O'Neill SL (2001). Wolbachia-mediated sperm modification is dependent on the host genotype in Drosophila. Proc $R$ Soc Lond B 268: 2565-2570.

McLeod MP, Qin X, Karpathy SE, Gioia J, Highlander SK, Fox GE et al. (2004). Complete genome sequence of Rickettsia typhi and comparison with sequences of other rickettsiae. I Bacteriol 186: 5842-5855.

Merçot H, Poinsot D (1998). ... and discovered on Mount Kilimanjaro. Nature 391: 853.

Montenegro H, Petherwick AS, Hurst GDD, Klaczko LB (2006). Fitness effects of Wolbachia and Spiroplasma in Drosophila melanogaster. Genetica 127: 207-215.

Mouton L, Henri H, Bouletreau M, Vavre F (2005). Multiple infections and diversity of cytoplasmic incompatibility in a haplodiploid species. Heredity 94: 187-192.

Oliver KM, Moran NA, Hunter MS (2005). Variation in resistance to parasitism in aphids is due to symbionts not host genotype. Proc Natl Acad Sci USA 102: 12795-12800.

O'Neill SL, Hoffmann AA, Werren JH (1997). Influential passengers. Inherited microorganisms and arthropod reproduction. Oxford University Press: New York.

Pannebakker BA, Loppin B, Elemans CPH, Humblot L, Vavre F (2007). Parasitic inhibition of cell death facilitates symbiosis. Proc Natl Acad Sci USA 104: 213-215.

Perlman SJ, Kelly SE, Zchori-Fein E, Hunter MS (2006). Cytoplasmic incompatibility and multiple symbiont infection in the ash whitefly parasitoid, Encarsia inaron. Biol Control 39: 474-480.

Perrot-Minnot MJ, Cheval B, Migeon A, Navajas M (2002). Contrasting effects of Wolbachia on cytoplasmic incompatibility and fecundity in the haplodiploid mite Tetranychus urticae. J Evol Biol 15: 808-817.

Perrot-Minnot MJ, Werren JH (1999). Wolbachia infection and incompatibility dynamics in experimental selection lines. J Evol Biol 12: 272-282.

Poinsot D, Merçot H (1997). Wolbachia infection in Drosophila simulans: does the female host bear a physiological cost? Evolution 51: 180-186.

Reed KM, Werren JH (1995). Induction of paternal genome loss by the paternal-sex-ratio chromosome and cytoplasmic incompatibility bacteria (Wolbachia - a comparative-study of early embryonic events. Mol Reprod Dev 40: 408-418.

Reynolds KT, Hoffmann AA (2002). Male age, host effects and the weak expression or nonexpression of cytoplasmic incompatibility in Drosophila strains infected by maternally transmitted Wolbachia. Genet Res 80: 79-87.

Ros VID, Breeuwer JAJ (2007). Spider mite (Acari: Tetranychidae) mitochondrial COI phylogeny reviewed: host plant relationships, phylogeography, reproductive parasites and barcoding. Exp Appl Acarol 42: 239-262. 
Stouthamer R, Breeuwer JAJ, Hurst GDD (1999). Wolbachia pipientis: microbial manipulator of arthropod reproduction. Annu Rev Microbiol 53: 71-102.

Toda S, Osakabe M, Komazaki S (2000). Interspecific diversity of mitochondrial COI sequences in Japanese Panonychus species (Acari: Tetranychidae). Exp Appl Acarol 24: 821-829.

Tram U, Fredrick K, Werren JH, Sullivan W (2006). Paternal chromosome segregation during the first mitotic division determines Wolbachia-induced cytoplasmic incompatibility phenotype. J Cell Science 119: 3655-3663.

Vala F, Breeuwer JAJ, Sabelis MW (2000). Wolbachia-induced 'hybrid breakdown' in the two-spotted spider mite Tetranychus urticae Koch. Proc R Soc Lond B 267: 1931-1937.

Vala F, Weeks A, Claessen D, Breeuwer JAJ, Sabelis MW (2002). Within- and between-population variation for Wolbachiainduced reproductive incompatibility in a haplodiploid mite. Evolution 56: 1331-1339.

Van Opijnen T, Breeuwer JAJ (1999). High temperatures eliminate Wolbachia, a cytoplasmic incompatibility inducing endosymbiont, from the two-spotted spider mite. Exp Appl Acarol 23: 871-881.

Vavre F, Fleury F, Varaldi J, Fouillet P, Bouletreau M (2000). Evidence for female mortality in Wolbachia-mediated cytoplasmic incompatibility in haplodiploid insects: Epidemiologic and evolutionary consequences. Evolution 54: 191-200.

Vavre F, Girin C, Bouletreau M (1999). Phylogenetic status of a fecundity-enhancing Wolbachia that does not induce thelyto$\mathrm{ky}$ in Trichogramma. Insect Mol Biol 8: 67-72.

Veneti Z, Clark ME, Zabalou S, Karr TL, Savakis C, Bourtzis K (2003). Cytoplasmic incompatibility and sperm cyst infection in different Drosophila-Wolbachia associations. Genetics 164: 545-552.

Weeks AR, Reynolds KT, Hoffmann AA, Mann H (2002). Wolbachia dynamics and host effects: what has (and has not) been demonstrated? Trends Ecol Evol 17: 257-262.
Weeks AR, Velten R, Stouthamer R (2003). Incidence of a new sex-ratio-distorting endosymbiotic bacterium among arthropods. Proc R Soc Lond B 270: 1857-1865.

Weeks AR, Stouthamer R (2004). Increased fecundity associated with infection by a Cytophaga-like intracellular bacterium in the predatory mite, Metaseiulus occidentalis. Proc $R$ Soc Lond B 271: S193-S195.

Weisburg WG, Barns SM, Pelletier DA, Lane DJ (1991). 16s ribosomal DNA amplification for phylogenetic study. J Bacteriol 173: 697-703.

Werren JH (1997). Biology of Wolbachia. Annu Rev Entomol 42: 587-609.

Werren JH, Windsor D, Guo LR (1995). Distribution of Wolbachia among neotropical arthropods. Proc R Soc Lond B 262: 197-204.

White JA, Kelly SE, Perlman SJ, Hunter MS (2009). Cytoplasmic incompatibility in the parasitic wasp Encarsia inaron: disentangling the roles of Cardinium and Wolbachia symbionts. Heredity (doi:10.1038/hdy.2009.5)

Wu M, Sun LV, Vamathevan J, Riegler M, Deboy R, Brownlie JC et al. (2004). Phylogenomics of the reproductive parasite Wolbachia pipientis wMel: A streamlined genome overrun by mobile genetic elements. Plos Biol 2: 327-341.

Zabalou S, Charlat S, Nirgianaki A, Lachaise D, Mercot H, Bourtzis K (2004). Natural Wolbachia infections in the Drosophila yakuba species complex do not induce cytoplasmic incompatibility but fully rescue the wRi modification. Genetics 167: 827-834.

Zchori-Fein E, Perlman SJ (2004). Distribution of the bacterial symbiont Cardinium in arthropods. Mol Ecol 13: 2009-2016.

Zurdo-Piñeiro JL, Rivas R, Trujillo ME, Vizcaino N, Carrasco JA, Chamber $\mathrm{M}$ et al. (2007). Ochrobactrum cytisi sp nov, isolated from nodules of Cytisus scoparius in Spain. Int J Syst Evol Microbiol 57: 784-788. 